\title{
TECHNOLOGY SUSTAINABILITY ASSESSMENT TO SUPPORT DECISION MAKING ON ENERGY PRODUCTION AT LOCAL SCALE
}

\author{
S. SALA \& V. CASTELLANI \\ University of Milano Bicocca, Department of Environmental Science, Italy.
}

\begin{abstract}
Considering climate issues, the Kyoto Protocol is the most important worldwide reference aimed at reducing greenhouse gases that cause climate change; going further, the recent European Climate and Energy Policy defines binding targets for 2020, that include increasing use of renewable energy (wind, solar, biomass, etc.) to $20 \%$ of total energy production. In order to identify the most suitable strategies to achieve this objective, an evaluation of some relevant issues that can affect the sustainability of possible renewable energy options is necessary. This study focus on technology sustainability assessment of energy production from forest biomass, defining a set of indicators to provide a decision support system (DSS) for local decision makers, enabling them to evaluate the environmental impacts, the resource availability and renewability, the feasibility of the technology in the local context and the social acceptance of the plant among the local community. The case study presented in this article refers to an Italian mountain community (Comunità Montana delle Alpi Lepontine) in northern Italy, where the assessment of environmental, economic and social sustainability of a plant producing electricity powered by Syngas coming from gasification of forest biomass was performed. The aim of the research was to develop a multidisciplinary DSS to assess the feasibility of the application and to define guidelines for sustainability assessment of technologies for energy production using forest biomass, identifying critical issues and potential areas of optimization.

Keywords: biomass, energy planning, energy technology assessment, gasification, renewable energy.
\end{abstract}

\section{INTRODUCTION}

Climate change represents one of the greatest environmental, social and economic threats facing the planet. Changes in the atmospheric concentration of Green House Gases (GHGs) are causing a rise in global temperature with effects on the sea level, on the frequency of extreme weather events like droughts and floods, and on agriculture and biodiversity, while also generating great impacts on the socio-economic side [1]. To contrast these effects, there is a need for actions, especially aimed to reduce GHGs concentration in the atmosphere by cutting of anthropogenic emissions.

The Kyoto protocol, signed by 195 Countries in 1997, entered into force in February 2005 and is the operational instrument of the United Nations Framework Convention on climate change. The protocol requires Industrialized Countries and those with transition economies to reduce to at least 5.2\% main anthropogenic emissions of GHGs during the 2008-2012 period. Moreover, the European Council has recently enacted the EU's Climate and Energy Policy [2] providing a major contribution to reduce climate change impact and trying to overcome difficulties in reaching Kyoto Protocol's objectives, and a Post Kyoto international policy is expected. European Climate and Energy policy fixes by 2020 a set of actions encompassing: cutting energy consumption by $20 \%$ of projected 2020 levels by improving energy efficiency, cutting GHGs by at least $20 \%$ of 1990 levels, and increasing use of renewable energy sources (wind, solar, biomass, etc.) to $20 \%$ of total energy production.

The European Environmental Agency assessed the potential quantity of European environmentally compatible biomass which is the quantity of biomass that is technically available for increased energy generation that does not pose threats to biodiversity, soil and water resources and that is in

(C) 2011 WIT Press, www.witpress.com

ISSN: 1743-7601 (paper format), ISSN: 1743-761X (online), http://journals.witpress.com

DOI: $10.2495 /$ SDP-V6-N3-251-267 
line with other current and future environmental objectives. Preliminary results indicate that the potential of environmentally compatible primary biomass for producing energy could increase from around 180 MTOE (Million Tons of Oil Equivalent) in 2010 to about 300 MTOE in 2030 (considering the bio-energy potential from agriculture, forests and waste) [3, 4]. Even if forest harvesting is a serious environmental problem at the global level (e.g. for deforestation in tropical areas), in some areas, and especially in Europe, carefully planned forest management is needed to prevent abandonment and degradation of these areas [5].

The term 'Biomass' covers a very large and very heterogeneous number of organic materials, vegetables or animals, which involve different ways of energy production. Energy production may be directly through combustion or indirectly through, as an example fermentation or gasification. The development of energy systems based on the use of biomass can be advantageous for the following reasons: widespread resources are available; biomass has the capacity to be incorporated into every energy sector (heating, power and transport) and bio-energy produced when needed; bio-fuels are generally bio-degradable and non-toxic, which is important when accidents occur. Nevertheless, bio-energy expansion encounters several barriers:

- costs of bio-energy technologies and resources;

- amount of externalities included in the cost calculations which strongly affects competitiveness;

- resource potentials and distributions;

- local land-use and environmental aspects, especially in the developing countries;

- administrative and legislative bottlenecks [6].

There are many biomass exploitation technologies, from the boilers that produce domestic heat, to central heating plants and combined heat and electricity plants for cogeneration. Thermo-chemical energy conversion processes ('dry way') are mainly used for forest biomass: thermo chemistry conversion plants are based on combustion, gasification and pyrolysis processes. In addition, some forest biomass is properly appropriate for the gasification process due to some features such as high volatility, high reactivity of carbon, low ash and sulphur content; moreover, fuels used to power an electricity generating engine can be obtained from biomass gasification and pyrolysis.

The use of biomass as an energy source can be considered sustainable in relation to: the reduction of energy dependency on energy imports; the increased security of supply; the climate change mitigation and the zero emission of $\mathrm{CO}_{2}$ in atmosphere in a global balance. Nevertheless, questions about the benefits of bio-based processes for energy production have been raised by researchers $[7,8]$, underlying that biological processes and bio-based products do not automatically imply better sustainability performance and that an overall impact assessment, that takes into account resource limits, rate of consumption and indirect effects, has to be conducted in order to assess sustainability of the whole process and of the technology involved.

A discussion paper of the Wuppertal Institute [9] has recently highlighted the need for an integrated assessment to derive guidelines for a sustainable biomass strategy. It is not possible to assume a positive balance for processes based only on the fact that they are bio-based, but it is necessary to perform exhaustive studies in a life cycle perspective, considering also site-specific characteristics (e.g. the local availability of raw material and the distance from the processing plant to the delivery point) [10]. Thus, the proposed methodology is aimed to perform a comparative assessment across alternative production scenarios and technologies. This approach should help to judge the relative sustainability of different project options, with an assessment that is tailored to the local features of the resource-production-consumption system. 


\subsection{Energy technology assessment}

According to the principle of subsidiarity, European Policy requires the involvement of local communities in energy planning at different levels, so it is important for local authorities to be aware of the benefits and costs of different energy strategies in order to find the most sustainable solution for their context, considering the economic, environmental and social perspective. This means that they need suitable instruments to assess sustainability of different policy scenarios, with specific reference to the sustainability of different kind of technological solutions for energy production at the local level.

Technology Assessment, as defined by the Society of German Engineers (VDI, Verein Deutscher Ingenieure) [11], is 'the planned, systematic, organized procedure that analysis the state of a technology and its possibilities, estimates direct and indirect technical, economic, health, environmental, human, social and other consequences of a technology, and possible alternatives, evaluates these consequences or call for other desirable developments based on defined goals and values, recommends possibilities for action and design to make reasoned decisions possible and realizable through appropriate bodies'.

Energy technology assessment related to biomass use can be a useful tool for helping different decision-makers and stakeholders to understand which role biomass exploitation technologies can have in their energy policies and for supporting the decision-making process in moving towards a sustainable energy future. Moreover, energy technology assessment applied to a specific context can help to identify which are the strengths and the weaknesses of the system under evaluation, with the aim to highlight critical issues and potential areas for optimization in order to improve the sustainability of the system.

In fact, to ensure the best result in term of sustainability of the implementation of a technology for energy production from wood biomass, local authorities (acting as decision makers in authorizing or not authorizing the plant), has to choose the best (and feasible) option about the site, the size and the technology used for the plant. This implies considering various factors such as the availability of wood biomass at a limited distance from the hypothetical site of the plant, the abundance of the biomass available for harvesting (amount of wood that can be harvested without stressing the forest renewal capacity) in order to define the most suitable size of the plant, the accessibility of the infrastructures that allow to the wood to be transported from the forest and to the site, and the economic sustainability of the plant (considering also possible incentives for renewable energy production) referred to the possible size options, etc.

Therefore there is a lot of information coming from different disciplines that have to be evaluated in an integrated manner to define possible scenarios and to be translated into a usable format for appropriate decision makers (e.g. public authorities that wish to define a sustainable energy strategy at local level or private businesses that want to invest in sustainable energy production).

Considering the complexity and the multidimensional features of this kind of assessment, a Decision Support System (DSS) can be a useful tool for the evaluation. DSS can be defined as interactive systems able to produce data and information and, in some cases, even promote understanding related to a given application domain in order to give useful assistance in resolving complex and ill-defined problems [12]. To produce relevant information for decision making about the sustainability of the options under evaluation, the DSS has to be composed by a multidisciplinary set of indicators considering environmental, economic and social sustainability aspects; moreover, the definition of sustainability indicators helps to introduce quantification, measurability and comparability in technology assessment studies [13]. 
This article presents a multidimensional DSS for sustainability technological assessment of forest biomass use for energy generation at local level, that takes into account the specific local conditions. The methodology leads to the definition of a set of sustainability indicators based on local environmental, economic and social context, with the aim of enlarging the perspective of evaluation and shifting from a theoretical comparison of different technologies (as it is, for instance, in Evans [14]) to a more practical assessment of technology feasibility and sustainability in a specific context.

According to Puy et al. [15], who developed a methodology for an Integrated Assessment of forest bio-energy systems in the Mediterranean basin areas, specific socio-ecologic factors need to be taken into account if forest biomass is to contribute decisively to securing renewable sources of energy in Europe. Among these key factors identified are property regimes, weak institutional capacity but also logistics and supply difficulties and the lack of economic profitability of forest products. Technological solutions alone, while important, are insufficient to ensure a prominent role of forest biomass management in the climate, landscape and sustainability energy policy challenge.

\section{METHODOLOGY}

The methodology developed for this study defines an integrated sustainability analysis process about the implementation of a system for energy use of forest biomasses, in order to address the decision making process towards the most sustainable option referring to the local context. To choose the best alternative in term of environmental, economic and social performance a comparison should be done among a number of different technologies. The main criterion to evaluate sustainability of technological solutions for energy production from forest biomasses [16] could be listed as follow: use of local resource considering carrying capacity of the system; short supply chain (defined following the Italian legislation reference of the resource use within $70 \mathrm{~km}$ distance from forest to production/supply site), GHGs compensation ability; reduction of overall environmental impact; financial profitability; capacity to generate positive economic and social effects in the local context.

In literature there are a considerable number of studies assessing the impact of RES (Renewable Energy Sources) deployment and evaluating the amount of materials used in relation to the energy produced by a specific RES energy system [17]. However, only some attempts to integrate environmental, social and economic aspect in RES assessment have been made [18]. Moreover, besides the environmental benefits and the economic incentives provided by international, national and regional programmes for RES development, there are some other factors that can strongly influence the decision about whether or not to implement a plant using RES, such as the economic profitability, the investment rate of return [19], and the acceptability of the plant from the local community [20].

Therefore the evaluation is made through a set of indicators about technological efficiency as well as environmental, economic and social sustainability. Some of the latter where specifically developed referring to the analyzed case study, aimed to assess environmental, economic and social sustainability of biomass use for energy production in the local context. For each indicator a specific procedure for the implementation and the evaluation of the performance has been developed. The assessment is site-specific: an optimum level of development of the considered system is based on existing conditions and a local supply chain wood-energy. The final result is the evaluation of the overall sustainability of the considered system in view of comparative assessment against other options.

The main phases of the technology sustainability assessment methodology proposed in Lacquaniti [21] and optimised and implemented for this study may be summarized as follows:

1. Development of a conceptual model for the assessment,

2. Analysis about available technological options for biomass exploitation to populate technological efficiency indicators, 
3. Definition of the indicator set (composed by environmental, economic and social sustainability indicators),

4. Analysis about local resources (to evaluate their energy content) analysis of environmental, social and economical condition to populate indicators of: resource availability, environmental impact, economic efficiency and social impact related to the specific technological option,

5. Definition of an optimum range of application based on benchmark and literature values,

6. Score attribution to each indicator, referred to the level of achievement of the optimum and development of an aggregated index measuring the comprehensive sustainability of the system,

7. Comparison among the sustainability level achieved by each technological option under evaluation.

Figure 1 shows the conceptual scheme for sustainability assessment according to our methodology. Following the steps illustrated before, a set of specific indicators is developed to assess the performance of a number of potential technological options for energy production using forest biomass. The approach adopted derives from multicriteria analysis techniques for decisions on projects/systems that may have potential environmental impacts. For the evaluation of each specific indicator, the methodology uses quantitative cardinal scales, tool for multi-criteria analysis application where all the indicators are related to a conventional scale with the aim of allowing comparability between different criteria and reducing heterogeneous measures to comparable values [22]. Moreover, the use of cardinal scales can be useful in evaluation of sustainability through a set of indicators because single indicators refer to different areas of investigation not directly comparable such as environmental, economic, social and technological issues.

In the present study some of the indicators composing the set established for evaluation are directly related to the specific technological application under evaluation, while others depend on the local context (environmental, economic, social and political features) in which the technology has to be implemented.

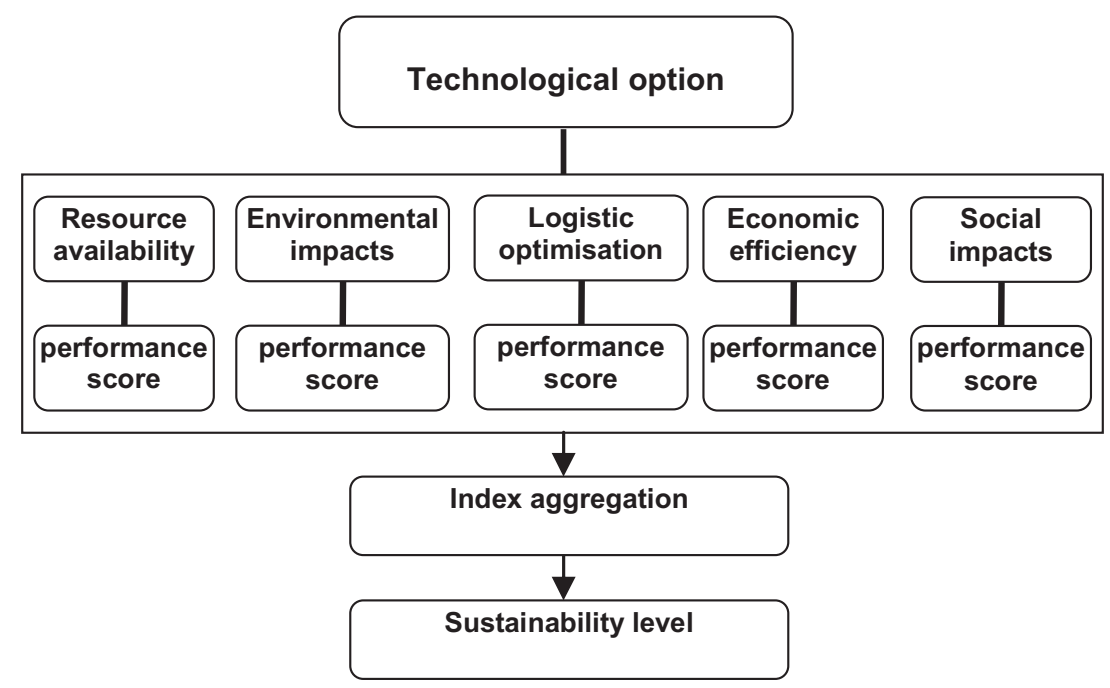

Figure 1: Technological sustainability assessment (modified from Lacquaniti [21]). 
The indicators composing the set are individually assessed by comparing the value obtained in the specific case study with potential value of optimum situation of implementation. Indices that refer to a conventional scale that takes values from 0 to 1 were associated to indicators values, depending on the performance of assessed indicator (value $\mathrm{x}$ ) compared with the performance of potential optimal solution (value 1). Finally, the comprehensive sustainability level achieved by the technological option derives from the score level of each indicator composing the set and it is expressed as a percentage of achievement referred to the optimal condition that can be reached according to the specific conditions of the local situation. The following equations illustrates in more detail the aggregation method that is used for the assessment: the sustainability of each issue is assessed in percentage terms by summing the standardized indices of each indicator and comparing this value with the sum of standardized indices of potential optimal situation:

$$
\begin{aligned}
& \text { Sustainability level of dimension } \mathrm{i}=\left(\sum \mathrm{x} / \sum \mathrm{x}^{1}\right) \times 100 \\
& \text { Sustainability of the technology }=\left[\sum(\mathrm{xi}) / \sum\left(\mathrm{xi}^{1}\right)\right] \times 100
\end{aligned}
$$

where $\mathrm{x}=$ value measured $\mathrm{x}^{1}=$ reference value (optimum); $\mathrm{i}=$ sustainability dimension considered (environmental, economic, social, technological).

The following paragraphs illustrate the indicators composing the set and the reference values adopted for defining the optimum to which the performance of each indicator has to be compared in order to assess the sustainability level of the system under evaluation.

\subsection{Technology option indicators}

Considering that the technology used for energy production is one of the most relevant aspects that determine the efficiency of the system and the level of environmental impacts (including both resource consumption and the amount of emissions generated), a specific group of indicators for taking into account some relevant aspects related to the technology adopted is developed. It includes: energy efficiency of the technology under evaluation, minimum amount of biomass required by the technology used and avoided $\mathrm{CO}_{2}$ emissions.

\subsubsection{Energy efficiency of the technology under evaluation}

The thermal and energy potential of the resource stock that we would like to exploit (which is one of the element that it is necessary to know for the evaluation of the sustainability of the system over a long term period, in addition to the amount of stock available) depends on the energy efficiency of the technology that it is supposed to be use in the conversion from heat to electricity. The electricity energy efficiency is measured in electric kiloWatt per hour $\left(\mathrm{kWh}_{\mathrm{e}}\right)$ produced per kilogram $(\mathrm{kg})$ of biomass used. The efficiency of the technology under evaluation is compared with the average efficiency of the technologies currently available on the market, which is $0.5 \mathrm{kWh}_{\mathrm{e}} / \mathrm{kg}$.

\subsubsection{Minimum amount of biomass required by the technology used}

It refers to the necessity to provide a minimum amount of biomass in order to ensure the best performance of the plant under evaluation; it depends obviously on the technical features of the chosen technology. The value is compared with the actual amount of biomass available within the short supply chain condition (i.e. using biomass coming from local forests). The information coming from this evaluation are needed for the assessment of the environmental indicator 'Biomass availability', in order to compare the amount of biomass needed and the amount of biomass available for exploitation at a local scale. 


\subsection{Resource availability}

The type and the amount of the biomass available for energy production can determine the feasibility and the efficiency of the system under evaluation, especially with respect to the availability of a local biomass stock that allows the system to be self sufficient (i.e. not depending on imports from outside the area, that can generate significant impacts especially due to the emissions coming from shipping the feedstock to the plant). Moreover, it is necessary to consider that due to different values of energy content in the raw material, some types of biomass can have higher energy content, i.e. a higher potential for energy production per mass unit, making it more suitable for energy production. Thus, indicators about biomass resource included in the set for environmental sustainability assessment refers to: biomass availability, energy content of the biomass and possible environmental impacts.

\subsubsection{Biomass availability}

To determine how much biomass is available for energy use it is necessary to know what is the production rate for the available biomass that can be used without depleting the natural capital (i.e. what is the carrying capacity of the local forest system) in the area. There are two kinds of information needed for this evaluation: the total amount of biomass in the area and the rate of growth of the stock (considering also that there could be other forms of demand for the wood biomass coming from the same area).

Moreover, it can be interesting to also consider the possibility to use non-homogeneous biomass, including residues coming from forestry and agriculture activities and from the organic fraction of urban waste $[23,24]$. Currently it is not easy to assess the availability of the first type of residues, while there is good monitoring about urban waste (and about the amount and quality of their organic fraction, including also garden residues) in the municipalities that have a separate collection system for this kind of waste.

\subsubsection{Biomass energy content}

The amount of energy embedded in the biomass can be expressed as kilojoule $(\mathrm{kJ})$ or kilocalories (kcal). To evaluate the effective energetic value of the biomass available it is necessary to consider the Lower Heating Value (LHV) that corresponds to the amount of heat generated during combustion for every single mass unit of biomass which is combusted and is expressed in $\mathrm{kJ} / \mathrm{kg}$. Multiplying the LHV for the amount of biomass available $(\mathrm{kg})$, it is possible to calculate the energetic value of the biomass $(\mathrm{kJ})$ that a specific area can provide. This value is compared with the total amount of energy consumption in the study area, to evaluate to the extent to which a proposed plant can contribute to the area's energy demand. The values are expressed in tonnes of oil equivalent, toe, to be comparable.

\subsection{Environmental impacts}

Environmental impact has to be taken into account because, even if the energy production from biomass is considered a sustainable use of resource, other aspects may affect the overall sustainability of the system.

\subsubsection{Environmental impacts}

The environmental impacts associated with biomass use for energy production have to be evaluated considering the technology used, the characteristic of the biomass and the specific conditions of the 
area. The possible impacts identified have to be evaluated referring to the existing environmental regulation, related to air, water, soil impacts and biodiversity.

\subsubsection{Avoided $\mathrm{CO}_{2}$ emissions}

Considering that biomass use for energy production is intended as a way to reduce the dependence on oil products and to reduce $\mathrm{CO}_{2}$ emissions from combustion, for sustainability evaluation it is necessary to quantify the amount of $\mathrm{CO}_{2}$ emissions avoided when compared with traditional energy plants. The method used in this study to evaluate avoided $\mathrm{CO}_{2}$ emissions was developed by ENEA (Italian National Agency for New Technologies, Energy and Sustainable Economic Development) and considers energy conversion efficiency of the technology used [25].

During all the processes for energy production starting from fossil sources, carbon contained in the fossil fuel is completely transformed to $\mathrm{CO}_{2}$ due to the reaction with the $\mathrm{O}_{2}$ from air. The rate of conversion depends on the amount of carbon contained in the fuel, so for each kind of fuel it is possible to identify a specific ' $\mathrm{CO}_{2}$ conversion factor' that defines how much $\mathrm{CO}_{2}$ is produced per unit of fuel combusted. Table 1 illustrates the $\mathrm{CO}_{2}$ factor for the most common types of fuel. It is important to note that in the case of biomass, the combustion generates $\mathrm{CO}_{2}$ coming from the amount of carbon contained in the biomass. However, this carbon has been subtracted from the atmosphere and fixed by the vegetation, so this can be considered as a closed loop that doesn't contribute to the increasing of the total amount of $\mathrm{CO}_{2}$ in the atmosphere; for this reason, the $\mathrm{CO}_{2}$ factor $\left(\mathrm{F}\left(\mathrm{CO}_{2}\right)\right)$ for biomass is considered equal to zero.

Considering the $\mathrm{CO}_{2}$ factor it is possible to estimate the amount of $\mathrm{CO}_{2}$ emissions generated by a specific energy production plant, simply calculating the ratio between the factor and the value of electric efficiency, according to the following formula:

$$
\mathrm{E}\left(\mathrm{CO}_{2}\right)=\mathrm{F}\left(\mathrm{CO}_{2}\right) / \mathrm{Eff}
$$

where $\mathrm{E}\left(\mathrm{CO}_{2}\right)=$ emissions $\left(\mathrm{kg} / \mathrm{MWh}_{\mathrm{e}}\right) ; \mathrm{F}\left(\mathrm{CO}_{2}\right)=\mathrm{CO}_{2}$ factor of the fuel $\left(\mathrm{kg} / \mathrm{MWh}_{\mathrm{t}}\right) ; \mathrm{Eff}=$ electric efficiency of the plant.

Comparing the value of electric efficiency of a proposed plant with a mean value of a traditional technology producing electricity from fossil fuels, the indicator is calculated as a percentage of emissions avoided due to the use of this technology instead of a traditional one.

\subsection{Logistics indicators}

Logistics plays a relevant role in determining the environmental impacts (e.g. GHG emissions due to transport) and the economic efficiency of the system. Difficulties to reach biomass (e.g. in forest areas) can generate higher costs for biomass extraction and energy production, resulting in lower

Table 1: $\mathrm{CO}_{2}$ factor $\left(\mathrm{kg} / \mathrm{MWh}_{\mathrm{t}}\right)$ for different energy sources [25].

\begin{tabular}{lc}
\hline Fuel & $\mathrm{F}\left(\mathrm{CO}_{2}\right)$ \\
\hline Natural gas & 205 \\
Oil & 255 \\
Coal & 340 \\
Wood biomass & 0 \\
\hline
\end{tabular}


competitiveness of the entire system. Logistics indicators selected consider the accessibility of the forests that are supposed to provide wood biomass for the plant and the distance from these sites to the plant site (i.e. the length of road transport that the system implies).

\subsubsection{Forest accessibility}

The indicator refers to the spatial characteristics of the forest in order to evaluate the accessibility and the possibility to easily reach the biomass that has to be harvested. The indicator considers the percentage of forest roads that is accessible to trucks (the optimum for accessibility is fixed in 100\%) taking into consideration the slope of the areas and the characteristics of the road network into the forest and in the surroundings.

\subsubsection{Biomass transport}

One of the aims of the implementation of a biomass energy production system is the valorisation of the local forest in order to create a short supply chain and to reduce the impacts generated by the transportation of the biomass itself. Thus it is important to consider the total distance from the various extraction points to the site of energy plant in order to verify if this objective of reduction could be fulfilled by the proposed localisation of the plant. The methodology includes two evaluations about transport: the first regards the number of trips that a truck loading $50 \mathrm{~m}^{3}$ of biomass has to undertake to provide all the biomass and the second regards the distance from the extraction points to the plant site. For the evaluation of the indicator in the case study presented in this article, the mean distance value for the system is compared with a reference value of $70 \mathrm{~km}$, which is the maximum distance allowed for transport within a short supply chain from the current legislation in Italy (Law 296/2006).

\subsection{Economic indicators}

Besides the considerations of the environmental sustainability of an energy production plant using local forest biomass in a short supply chain, the economic viability of the entire system (cost of biomass and of the technology compared with the foreseen profit) is a crucial point that will interfere with the decision of entrepreneurs or public authorities on whether or not to implement it in the specific area. For this reason, to be effectively useful for local decision makers, the decision support system has to necessarily include indicators about economic sustainability, i.e. to evaluate costs and benefits that the system can generate in the specific context considered. The indicators included in our methodology refer to: cost of the biomass, cost the technology, labour cost, production cost per energy unit, cost of emissions mitigation and profits (including possible incentives for renewable energy).

\subsubsection{Energy production cost}

The final cost of energy production per energy unit is calculated dividing the total costs of the system (including cost for the technology, cost of the biomass and labour cost) per the amount of energy produced. The final cost $\left(/ \mathrm{kWh}_{\mathrm{e}}\right)$ is then compared with the cost per $\mathrm{kWh}_{\mathrm{e}}$ of electricity production with traditional technologies.

\subsubsection{Economic profitability of the system}

The indicator evaluates the profitability of the system considering the predicted cash flows and the time for investment pay-off and profit generation by the plant, (evaluating the profits coming from selling the energy produced and the possible economic incentives for using renewable sources in energy production). 


\subsubsection{Labour cost}

To estimate labour cost for the entire system it is necessary to consider the exact number of people employed (for forest management, harvesting, biomass transport and energy production) and their salary (according to the national contract standards for each sector). The indicator measures the role of labour cost with respect to the total cost of the system.

\subsubsection{Cost for $\mathrm{CO}_{2}$ reduction}

The cost is calculated dividing the total cost of the system per the amount of avoided $\mathrm{CO}_{2}$ emissions.

\subsubsection{Social indicators}

Considering that one of the objectives in establishing a short supply chain using local wood biomass is also provide social benefits to the local community through the valorisation of the forest and the creation of labour opportunities, it is important to evaluate the social sustainability of the system that is going to be created. Social sustainability indicators consider: social acceptability of the intervention, labour opportunities, the role of local actors and land ownership (public or private) of the areas that should provide biomass.

\subsubsection{Social acceptability}

Evaluation of the attitude of the local community towards the energy production plant. The investigation can be performed through sample survey among the population, e.g. through CATI (Computer Assisted Telephone Interviewing). The indicator considers the percentage of agreement expressed by the interviewees.

\subsubsection{Creation of job opportunities}

The indicator evaluates the social benefit in term of new job opportunities created by the implementation of the system. It consists in a qualitative evaluation; the classes for evaluation are:

- no job opportunities $=0$;

- part time job positions $=0.5$;

- full time job positions $=1$.

\subsubsection{Actors involved}

The indicator evaluates the feasibility of the system considering the availability of qualified actors able to implement the whole system in the local context (for example, Small and Medium Enterprises (SMEs) for harvesting and logging).

\subsubsection{Homogeneity of forest ownership}

The ownership of the forest that should provide the biomass is a crucial point in the evaluation of the system, especially regarding the price of biomass (a public owner could decide to use the biomass for a public plant with no additional costs, as is it for the case study presented in this article, while in the case of areas belonging to private owners, it would be necessary to verify the willingness to sell the biomass and its possible price). The indicator measures the percentage of homogeneity distribution of public and private areas (assuming the fragmented path can reduce the feasibility of the system).

\section{CHARACTERISTICS OF THE CASE STUDY}

The case study presented in this article refers to the sustainability assessment of the implementation of a wood biomass based energy production system in the Alpi Lepontine Mountain Community (CMAL), which is a mountain area of Lombardy Region, in Northern Italy. 
Alpi Lepontine area has an extent of 18,469 ha; the territory is mainly mountainous and includes 6844 ha of forest, which is essentially not managed. Currently, wood biomass is used predominantly in domestic biomass heating systems, which are characterized by a very low efficiency and generate a lot of fine particulate matter emissions. For this reason, local authorities are interested in evaluating innovative uses for energy (heat and electricity) production using wood biomass, especially for public buildings supply.

The system under evaluation in this study consists of a combined heat and electricity production plant, using Syngas obtained from wood biomass gasification; the plant is composed of modules with a power size of $250 \mathrm{~kW}$ and would use biomass coming from the local forests managed by Public Authorities, according to the management plans defined by the local forest management office. Based on the results of a preliminary meeting with a technical expert and some representatives of the Regional Agency for Forest Management (ERSAF) about the most efficient working conditions for the plant and the possible amount of biomass available with respect to the carrying capacity of the local forest ecosystem The following hypothesis for the system has been defined: plant consisting of one module of $250 \mathrm{~kW}$ power size, working $8200 \mathrm{~h} /$ year (the remaining $560 \mathrm{~h} \mathrm{left}$ for maintenance operations), needing $2132 \mathrm{t} /$ year of dry wood biomass as raw material and producing $2050 \mathrm{MWh} /$ year of electricity.

The sustainability of this hypothetical system that should be implemented in the Alpi Lepontine Mountain Community has been analyzed according to the methodology illustrated in Section 2 in order to evaluate its feasibility and sustainability in the local context and to provide useful information to local decision makers about possible threats (especially referring to environmental impacts and excessive biomass exploitation) and possible improvements of the system before its actual implementation.

\section{RESULTS}

The set of indicators presented in Section 2 was applied to Alpi Lepontine Mountain Community area, in order to support the sustainability assessment of the energy production system designed for the area and illustrated in Section 3.

Tables 2-5 illustrate each sustainability issue (environmental, economic and social), the indicators' classes and the score assessed for the case study. In addition, the performance of the area of study for each issue is compared with the reference value of the optimal solution, assumed as a $100 \%$ score and obtained by the sum of the best performance for each indicator (shown by a grey cell in the tables).

The definition of standards for the indicators, considering benchmark values, minimum and maximum, and for the definition of score classes is based on:

a Standards determined by international, European and national policy targets or laws (A)

b Best Available Technologies (BAT) documentation (B)

c Physical limits (resources, operational capacity) (C)

d Benchmarking with the best regional or national situations (D)

e Literature review (E)

f Expert judgement $(\mathrm{F})$

The methodology, therefore, could be affected by different sources of uncertainties, to be considered in case of comparative assessment:

- Parameter uncertainty due to input parameters (e.g. mass flows);

- Temporal and spatial variability related to some default values used to perform the evaluations when direct data are not available.

- Uncertainty due to subjective/expert judgment. 
As Tables 2-5 show, some of the indicators included in the methodological framework cannot be evaluated because of the lack of information about those issues. Nevertheless, this lack of information was included in the evaluation and considered as a negative contribution to the sustainability of the system, applying a precautionary principle. For this reason, social sustainability of the system is

Table 2: Environmental indicators.

\begin{tabular}{|c|c|c|c|c|c|c|}
\hline $\begin{array}{l}\text { Envir } \\
\text { indic }\end{array}$ & iental & $\begin{array}{l}\text { Reference } \\
\text { values }\end{array}$ & Scores & $\begin{array}{l}\text { Value for the } \\
\text { case study }\end{array}$ & $\begin{array}{l}\text { Score for } \\
\text { the case } \\
\text { study }\end{array}$ & $\begin{array}{c}\text { Source } \\
\text { for the } \\
\text { definition of } \\
\text { the optimal } \\
\text { score }\end{array}$ \\
\hline TE & $\begin{array}{l}\text { Technological } \\
\text { efficiency } \\
\text { (kWhe/kg) }\end{array}$ & $\begin{array}{c}\text { No info } \\
0-0.25 \\
0.26-0.50 \\
0.51-0.75 \\
0.76-0.99 \\
>1\end{array}$ & $\begin{array}{c}\mathrm{n} . \mathrm{a} \\
0 \\
0.25 \\
0.5 \\
0.75 \\
1\end{array}$ & 2 & 1 & B \\
\hline BA & $\begin{array}{l}\text { Biomass } \\
\text { availability } \\
\text { (ratio between } \\
\text { availability and } \\
\text { needs) }\end{array}$ & $\begin{array}{c}\text { No info } \\
0-0.25 \\
0.26-0.50 \\
0.51-0.75 \\
0.76-0.99 \\
>1\end{array}$ & $\begin{array}{c}\mathrm{n} . \mathrm{a} \\
0 \\
0.25 \\
0.5 \\
0,75 \\
1\end{array}$ & 0.89 & 0.75 & $\mathrm{C}$ \\
\hline $\mathrm{AE}$ & $\begin{array}{c}\text { Avoided } \mathrm{CO}_{2} \\
\text { emissions } \\
\left(\mathrm{tCO}_{2} / \mathrm{y}\right)\end{array}$ & $\begin{array}{c}\text { No info } \\
0 \% \\
0.1-3 \% \\
4-10 \% \\
11-20 \% \\
>20 \%\end{array}$ & $\begin{array}{c}\text { n.a. } \\
0 \\
0.25 \\
0.5 \\
0.75 \\
1\end{array}$ & 0.3 & 0.25 & A \\
\hline EI & $\begin{array}{l}\text { Environmental } \\
\text { impacts }\end{array}$ & $\begin{array}{c}\text { No info } \\
\text { Impacts beyond } \\
\text { law limits } \\
\text { Impacts within } \\
\text { law limits } \\
\text { Negligible } \\
\text { impacts }\end{array}$ & $\begin{array}{c}\mathrm{n} . \mathrm{a} \\
0 \\
0.5 \\
\\
1\end{array}$ & $\begin{array}{l}\text { Within law } \\
\text { limits }\end{array}$ & 0.5 & A \\
\hline FA & $\begin{array}{l}\text { Forest } \\
\text { accessibility }\end{array}$ & $\begin{array}{c}\text { No info } \\
\text { No paths } \\
\text { Paths partially } \\
\text { accessible } \\
\text { Paths totally } \\
\text { accessible } \\
\text { Dedicated paths } \\
\text { for harvesting }\end{array}$ & $\begin{array}{c}\mathrm{n} . \mathrm{a} \\
0 \\
0.5 \\
\\
0.75 \\
\\
1\end{array}$ & $\begin{array}{c}\text { Partially } \\
\text { accessible }\end{array}$ & 0.5 & $\mathrm{C}$ \\
\hline
\end{tabular}


Table 2: Continued

\begin{tabular}{lccccc}
\hline BT $\quad$ Biomass & No info & n.a & & A \\
& $>80 \mathrm{~km}$ & 0 & & & \\
& $51-80 \mathrm{~km}$ & 0.5 & & & \\
& $6-50 \mathrm{~km}$ & 0.75 & $\mathbf{1 1 . 6}$ & $\mathbf{0 . 7 5}$ & \\
& $0-5 \mathrm{~km}$ & 1 & & & \\
& & $\mathbf{6}$ & & & $100 \%$ \\
Optimal solution & & & $\mathbf{3 . 7 5}$ & $62 \%$ \\
Case study & & & &
\end{tabular}

Bold values are the values referred to the case study.

Table 3: Economic indicators.

\begin{tabular}{|c|c|c|c|c|c|c|}
\hline \multicolumn{2}{|c|}{ Economic indicators } & $\begin{array}{c}\text { Reference values } \\
\text { No info } \\
0-0.25\end{array}$ & $\begin{array}{c}\text { Scores } \\
\text { n.a } \\
0 \\
0.25\end{array}$ & $\begin{array}{c}\text { Value for } \\
\text { the case } \\
\text { study }\end{array}$ & $\begin{array}{l}\text { Score for } \\
\text { the case } \\
\text { study }\end{array}$ & $\begin{array}{c}\text { Source for } \\
\text { the } \\
\text { definition } \\
\text { of the } \\
\text { optimal } \\
\text { score }\end{array}$ \\
\hline $\mathrm{PC}$ & $\begin{array}{l}\text { Energy production } \\
\text { cost }(€ / \mathrm{kWh})\end{array}$ & $\begin{array}{c}\text { No info } \\
0-0.25 \\
0.26-0.5 \\
0.5-0.75 \\
1 \\
>1\end{array}$ & $\begin{array}{c}\text { n.a } \\
0 \\
0.25 \\
0.5 \\
0.75 \\
1\end{array}$ & 0.43 & 0.5 & D \\
\hline EP & Economic profitability & $\begin{array}{c}\text { No info } \\
0-0.99 \\
1 \\
1-1.5 \\
1.6-2 \\
>2\end{array}$ & $\begin{array}{c}\mathrm{n} . \mathrm{a} \\
0 \\
0.25 \\
0.5 \\
0.75 \\
1\end{array}$ & 2.78 & 1 & $\mathrm{D}$ \\
\hline $\mathrm{LC}$ & $\begin{array}{l}\text { Labour cost } \\
\text { (ratio with respect } \\
\text { to total management } \\
\text { costs) }\end{array}$ & $\begin{array}{c}\text { No info } \\
\quad=1 \\
0.61-1 \\
0.2-0.6 \\
0.1-0.2 \\
<0.1\end{array}$ & $\begin{array}{c}\mathrm{n} . \mathrm{a} \\
0 \\
0.25 \\
0.5 \\
0.75 \\
1\end{array}$ & 0.56 & 0.5 & A \\
\hline \multicolumn{2}{|c|}{ Optimal solution } & & 3 & & & $100 \%$ \\
\hline \multicolumn{2}{|c|}{ Case study } & & & & 2 & $66 \%$ \\
\hline
\end{tabular}

Bold values are the values referred to the case study. 
Table 4: Social indicators.

\begin{tabular}{|c|c|c|c|c|c|c|}
\hline \multicolumn{2}{|c|}{ Social indicators } & $\frac{\text { Reference values }}{\text { No info }}$ & Scores & $\begin{array}{l}\text { Value for } \\
\text { the case } \\
\text { study }\end{array}$ & $\begin{array}{c}\text { Score for } \\
\text { the case } \\
\text { study }\end{array}$ & $\begin{array}{c}\text { Source for } \\
\text { the } \\
\text { definition } \\
\text { of the } \\
\text { optimal } \\
\text { score }\end{array}$ \\
\hline SA & $\begin{array}{l}\text { Social acceptability } \\
\text { (share of the local } \\
\text { community that } \\
\text { express positive attitude } \\
\text { through surveys) }\end{array}$ & $\begin{array}{c}\text { No info } \\
0-30 \% \\
31-50 \% \\
51-75 \% \\
76-99 \% \\
100 \%\end{array}$ & $\begin{array}{c}\text { n.a } \\
0 \\
0.25 \\
0.5 \\
0.75 \\
1\end{array}$ & No info & n.a. & F \\
\hline JO & $\begin{array}{l}\text { Job opportunities } \\
\text { (nr of jobs created) }\end{array}$ & $\begin{array}{c}\text { No info } \\
\text { No jobs } \\
\text { Part time jobs } \\
\text { Full time jobs }\end{array}$ & $\begin{array}{c}\text { n.a } \\
0 \\
0.5 \\
1\end{array}$ & Part time & 0.5 & $\mathrm{~B}, \mathrm{~F}$ \\
\hline $\mathrm{FH}$ & $\begin{array}{l}\text { Homogeneity of forest } \\
\text { ownership (share of } \\
\text { the forest owned by } \\
\text { the same subject) }\end{array}$ & $\begin{array}{l}\text { No info } \\
<30 \% \\
30-60 \% \\
61-100 \%\end{array}$ & $\begin{array}{c}\mathrm{n} . \mathrm{a} \\
0 \\
0,5 \\
1\end{array}$ & No info & n.a. & $\mathrm{B}, \mathrm{E}$ \\
\hline \multicolumn{2}{|c|}{ Optimal solution } & & 3 & & & $100 \%$ \\
\hline \multicolumn{2}{|c|}{ Case study } & & & & 0.5 & $16 \%$ \\
\hline
\end{tabular}

Bold values are the values referred to the case study.

Table 5: Comprehensive result of sustainability technology assessment in Alpi Lepontine.

\begin{tabular}{l|rr}
\hline Optimal solution & 12 & $100 \%$ \\
Case study & 6.25 & $52 \%$ \\
\hline
\end{tabular}

scored at $16 \%$ of the optimal condition instead of $50 \%$, as it would be if referred only to the optimal score of the accounted indicator.

The environmental and economic sustainability performance of the system under evaluation is quite good (respectively $62 \%$ and $66 \%$ ) even if there are some aspects that can be improved (e.g. environmental impacts), while the social sustainability is very low (16\%), especially because of the lack of information about this issue, as explained before.

As for the comprehensive evaluation of the sustainability performance of the technological solution under evaluation, which is obtained aggregating the total results for environmental, economic and social issues as explained in Section 2, the sustainability level achieved is 52\%; it means that there are several aspects that should be improved before the system can be implement in the area and generate positive effects. 
Table 6: Summary of indicators' scores.

\begin{tabular}{|c|c|c|}
\hline Indicator & Sustainability level & $\%$ \\
\hline TE & & 100 \\
\hline BA & & 75 \\
\hline $\mathrm{AE}$ & & 25 \\
\hline EI & & 50 \\
\hline FA & & 50 \\
\hline BT & & 75 \\
\hline PC & & 50 \\
\hline EP & & 100 \\
\hline $\mathrm{LC}$ & & 50 \\
\hline $\mathrm{JO}$ & & 50 \\
\hline
\end{tabular}

An overview of the scores obtained by the indicators composing the set (Table 6) can help to identify which are the issues that ensure higher sustainability performances and which are the ones that need further development in order to improve their sustainability performance (i.e. to improve sustainability of the system under evaluation).

Even if TE (technological energy conversion efficiency) and EP (economic profits) get a sustainability level of $100 \%$, BA (biomass available for energy production) gets $75 \%$ and indicators depending from local condition such as FA (accessibility related to forest paths), and JO (ability to create profitable job opportunities for the local community) gets only 50\%. This means that, even if the technology is efficient and profitable, its implementation in the area of Alpi Lepontine could encounter some difficulties due to the local conditions and thence result in a system less sustainable than the optimal one.

Thus, in order to improve sustainability of the system that has been designed by local decision makers, it is necessary to identify solutions to overcome the limits highlighted by the assessment, for instance, a deeper investigation of the social acceptability of the plant and the involvement of local businesses to find the way to make the projected system an chance for job creation and local development improvement.

\section{CONCLUSIONS}

The shift to renewable energy is one of the current major tasks in facing climate change and promoting more sustainable production and consumption patterns in the energy sector, especially if referred to small scale plants using local resources in a short supply chain and providing opportunities for sustainable development at a local scale. Nevertheless, the sustainability of these kinds of systems has not been taken for granted in all the operational conditions, so a detailed sustainability technology assessment of the design system for energy production has to be performed with the aim to prove useful information for local decision makers and to support their decisions about the choice of the optimal solution for the local context.

Moreover, it has to be recognized that besides environmental sustainability, the economic profitability (which is related also to the technical feasibility in the local context) and the social acceptability of the 
system can be crucial factors in determining whether or not to implement a specific technology in a specific area. The sustainability evaluation should include a comprehensive assessment of environmental, economic and social sustainability of the entire system under evaluation.

Thence the Decision Support System presented in this paper can be considered an operational and easily understandable tool for the sustainability evaluation of a local plan for biomass use in energy production. One of the most interesting aspects of this methodology is that it is possible to identify strengths and weaknesses of the system under investigation, supporting decision makers in the definition of actions able to improve sustainability with an optimal cost-benefit effectiveness.

Moreover, the methodology focuses on the feasibility assessment of the implementation of a specific technology in a specific area, considering all the relevant aspects in the local context (e.g. local biomass availability, community acceptance, environmental impact, economic costs, etc) in order to perform a sustainability assessment which considers not only the performance of the technology under evaluation in an ideal optimal condition, but also highlights the existing operational limits for an effective implementation in the area under investigation.

Uncertainties in the evaluation may be due to some subjective evaluations that have to be integrated in the indicators sets. Nevertheless, the methodology and the related open dashboard of indicators allow identifying where the performance of the indicators could be affected by subjective perspectives and where it is possible to increase the sustainability of the chosen technology/solution acting towards a better performance of the weak points/indicators.

The interesting feature of the methodology relies on the possibility of understanding areas of interventions to increase sustainability of the technology implementation, with respect to local context and resources. In comparative assessment, the methodology allows us to compare ACROSS different alternatives to judge the relative sustainability of different project options. Capability of tailoring sustainability solutions to local conditions is a crucial challenge for the next future of technology sustainability assessment.

\section{ACKNOWLEDGEMENTS}

The authors would like to thank Lino Lacquaniti for data collection and processing. The research activity was funded by the Province of Como within the project 'Grande Progetto di Montagna Bilancio di sostenibilità ambientale della filiera-legno energia nella Provincia di Como’.

\section{REFERENCES}

[1] IPCC. Climate change 2007. Contribution of Working Groups I, II and III to the Fourth Assessment Report of the Intergovernmental Panel on Climate Change. Core Writing Team, eds. R.K. Pachauri and A. Reisinger, IPCC: Geneva, Switzerland, pp 104, 2007.

[2] European Commission. An energy policy for Europe, COM (2007) 1 final, 2007.

[3] EEA, Climate change and a European low-carbon Energy System. EEA Report No 1/2005.

[4] European Commission. Biomass action plan, COM (2005) 628 final, 2005.

[5] Fujimori, T., Ecological and silvicultural strategies for sustainable forest management. Elsevier: Amsterdam, The Netherlands, 2001.

[6] EUBIA. The European Biomass Industry Association, www.eubia.org, accessed Sept. 2009.

[7] Kanzig, J., Anex, R. \& Jolliet, O., Conference report of the international workshop on assessing the sustainability of bio-based products. International Journal of LCA, 8(5), pp. 313-314, 2004. doi:http://dx.doi.org/10.1007/BF02978927

[8] Goldemberg, J. \& Teixeira Coelho, S., Renewable energy-traditional biomass vs. modern biomass. Energy Policy, 32, pp. 711-714, 2004. doi:http://dx.doi.org/10.1016/S0301-4215(02)00340-3 
[9] Bringezu, S., Ramesohl, S., Arnold, K., Fischedick, M., von Geibler, J., Liedtke, C. \& Schütz, H., What we know and what we should know towards a sustainable biomass strategy. A discussion paper of the Wuppertal Institute, n. 163, ISSN 0949-5266, 2007.

[10] Kim, S. \& Dale, B.E., Cumulative energy and global warming impact from the production of biomass for biobased products. Journal of Industrial Ecology, 7(3-4), pp. 147-162, 2004.

[11] VDI-Richtlinie 3780: Technikbewertung - Begriffe und Grundlagen, Beuth, Berlin, 1991.

[12] Cavallaro, F. \& Ciraolo, L., A multicriteria approach to evaluate wind energy plants on an Italian island. Energy Policy, 33, pp. 235-244, 2005. doi:http://dx.doi.org/10.1016/ $\underline{\text { S0301-4215(03)00228-3 }}$

[13] Jischa, M.F. Sustainable development and technology assessment. Chem Eng Technol, 21(8), pp. 629-636, 1998. doi:http://dx.doi.org/10.1002/(SICI)1521-4125(199808)21:8<629:: AID-CEAT629>3.0.CO;2-Q

[14] Evans, A., Strezov, V. \& Evans, T.J. Assessment of sustainability indicators for renewable energy technologies. Renewable and Sustainable Energy Reviews, 13, pp. 1082-1088, 2009. doi:http://dx.doi.org/10.1016/j.rser.2008.03.008

[15] Puy N., Tabara D., Bartroli Molins J., Bartroli Almera J. \& Rieradevall J. Integrated assessment of forest bioenergy systems in Mediterranean basin areas: the case of Catalonia and the use of participatory IA-focus groups. Renewable and Sustainable Energy Reviews, 12, 5, pp. 1451-1464, 2008. doi:http://dx.doi.org/10.1016/j.rser.2007.01.017

[16] Komiyama, H., Mitsumori, T., Yamaji, K. \& Yamada, K., Assessment of energy systems by using biomass plantation. Fuel, 80, pp. 707-715, 2001. doi:http://dx.doi.org/10.1016/ $\underline{\text { S0016-2361(00)00132-0 }}$

[17] Afgan, N.H., Carvalho, M.G. \& Nikolai, V., Energy system assessment with sustainability indicators. Energy Policy, 28, pp. 603-612, 2000. doi:http://dx.doi.org/10.1016/ $\underline{\text { S0301-4215(00)00045-8 }}$

[18] Del Rio, P. \& Burguillo, M., Assessing the impact of renewable energy deployment in local sustainability: towards a theoretical framework. Renewable and Sustainable Energy Reviews, 12, pp. 1325-1344, 2008. doi:http://dx.doi.org/10.1016/j.rser.2007.03.004

[19] Del Rio, P., Encouraging the implementation of small renewable electricity CDM projects: an economic analysis of different options, Renewable and Sustainable Energy Reviews, 11, pp. 1361-1387, 2007. doi:http://dx.doi.org/10.1016/j.rser.2005.12.006

[20] Assefa, G. \& Frostell, B., Social sustainability and social acceptance in technology assessment: a case study of energy technologies. Technology in Society, 29, pp. 63-78, 2007. doi:http:// dx.doi.org/10.1016/j.techsoc.2006.10.007

[21] Lacquaniti, P. \& Sala, S., Energy from biomass a decision support system for integrating sustainability into technology assessment. A.A. Mammoli, C.A. Brebbia \& V. Popov (a cura di), Energy and Sustainability II, Wit Press, pp. 291-302, 2009.

[22] Zeppetella, A., Bresso, M. \& Gamba, G., Valutazione ambientale e processi di decisione: metodi e tecniche di valutazione di impatto ambientale, ed. La Nuova Italia Scientifica, Roma, 1992.

[23] Damery, D., Benjamin, M., Kelty, M. \& Lilieholm, R.J., Developing a sustainable forest biomass industry: case of the US northeast, eds C.A. Brebbia, M. Neophytu, E. Beriatos, I. Ioannu \& A.G. Kungolos. Sustainable Development and Planning IV, Wit Press, pp. 21-30, 2009. ISBN: 978-1-84564-181-8.

[24] Lavoie, J.M., Chornet, M., Chornet, E., Biomass refineries: relationship between feedstock and conversion approach, eds A.A. Mammoli \& C.A. Brebbia, Energy and Sustainability II, Wit Press, pp. 291-302, vol. 121, 2009. ISBN: 978-1-84564-191-7.

[25] ENEA. Libro bianco per la valorizzazione energetica delle fonti rinnovabili, 1999. 